\title{
Research on Financial Exclusion in Ethnic Areas
}

\author{
Zhou Yucheng ${ }^{1}$, Wang Juan ${ }^{2}$
}

${ }^{1}$ School of Economics, South-Central University for Nationalities, Wuhan 430000, China
${ }^{2}$ Beijing Institute of Tracking and Telecommunication Technology, Beijng, 100094, China

\begin{abstract}
This article mainly studies the national minority areas. First, it systematically sorts out the financial exclusion theory and the financial development literature of the minority areas, and combines the economic and financial data at the provincial and county levels to empirically analyze the financial exclusion in the minority areas. The status quo, the influencing factors and the consequences of this, and some suggestions for managing financial exclusion in ethnic areas.
\end{abstract}

Keywords: Ethnic Regions, Financial Exclusion, Regression Analysis

\section{Introduction}

The study of financial exclusion began in the early 1990s (Leyshon \& Thrift, 1993, 1994, 1995). At the beginning, it was mainly considered that under the influence of geographical location and geographical distribution, the research on the influence of the distribution of financial institutions on financial services and The impact of local financial development. Since then, financial exclusion has received high attention internationally due to its very extensive practical and practical significance. The research content is also different from the earlier period. It no longer focuses on geographic research, but has turned to the humanistic research on financial exclusion (Ford \& Rowlingson , 1996: Kempson \& Whyley, 1998; Beck et al, 2007). On the one hand, it pays attention to the impact of social, institutional, and cultural factors on financial exclusion, as well as the consequences of financial exclusion on the social economy.

Financial exclusion is essentially a market failure. When the market fails, the allocation of resources is unfair, and there are opportunities for Pareto improvement. The existence of financial exclusion has caused some disadvantaged economic entities to be excluded by mainstream financial products and financial services, and this has prevented these entities from receiving equal treatment in the distribution of financial resources, which has caused changes in the flow of financial resources and led to financial resources. The configuration is unreasonable. Financial exclusion is affected by the internal market mechanism, which in turn is not conducive to the improvement of social welfare and hinders the continuous and efficient operation of the market mechanism.

The emergence of the concept of "financial exclusion" is inevitable for a certain stage of social development. This concept first appeared in countries with a high degree of financialization such as the United Kingdom and the United States. Starting from the existing Western theories and combining with China's actual conditions, research on the formation mechanism, effects and solutions of financial exclusion, and the strong demands of financial exclusion groups or regions, this is very beneficial to the continuous progress and development of Chinese society . Our society is currently undergoing a transition, and many social problems have emerged, such as the gap between urban and rural areas, the polarization between the rich and the poor, and the imbalance of regional development, which severely hinders the continued development of our society. Financial exclusion is precisely the problem of social imbalance in the financial field.

my country is a unified multi-ethnic country. Promoting the economic and social development of ethnic regions is an indispensable part of the policy of building a well-off society in an all-round way. It is also conducive to consolidating the unity among ethnic groups and has a very positive impact on maintaining social stability and reducing regional differences. To achieve the goal of promoting the development of ethnic regions, a sound financial system is needed to provide support. However, due to the influence of historical and practical factors, there is a relatively common phenomenon of financial exclusion in ethnic areas in our country, which hinders the social and economic development of ethnic areas seriously.

\section{The current situation of financial exclusion in China's ethnic areas \\ After investigation, the author studies the current situation of financial exclusion in ethnic areas, which is mainly reflected in the following aspects.}

\subsection{Distribution of financial outlets in ethnic areas} According to the data released on the website of the China Banking Regulatory Commission in May 2017,

This article is published under the terms of the Creative Commons Attribution License 4.0 Author(s) retain the copyright of this article. Publication rights with Alkhaer Publications. Published at: http://www.ijsciences.com/pub/issue/2020-08/

DOI: 10.18483/ijSci.2368; Online ISSN: 2305-3925; Print ISSN: 2410-4477 
there are currently 14,362 business outlets of major banking financial institutions in my country's ethnic provinces, accounting for $10.23 \%$ of the total number of business outlets in the country. From the perspective of regional distribution, ethnic regions account for $58.91 \%$ of the country's land area, and only have $10.23 \%$ of the country's banking outlets, with an average of 0.0026 outlets per square kilometer, while the national average is 0.0146 , which is much higher than in ethnic areas, it can be seen that the distribution of outlets in ethnic areas is too small and the density is too low. From the perspective of population distribution, ethnic regions have $14.26 \%$ of the country's population and $10.23 \%$ of the country's banking outlets, with an average of 0.76 per 10,000 people, which is lower than the national level of 1.01, but the gap is not large. (Note: The area and population data of each province comes from the National Bureau of Statistics, as of the end of 2016).

\subsection{Employees in financial institutions in ethnic areas}

In the "2016 China Regional Financial Operation Report" and "2016 Provincial and Municipal Financial Operation Report" issued by the People's Bank of China in 2017, as of the end of 2016, there were 460,272 employees in financial institutions in ethnic minority areas in China, accounting for $12.12 \%$, this proportion is still low. The average number of employees per 10,000 people in ethnic areas is 21.97 , still lagging behind the national average of 27.51 . Among the provinces in the ethnic regions, Inner Mongolia has the largest number of employees, reaching 101,818 , accounting for $22.12 \%$ of the ethnic regions and $2.68 \%$ of the country. Tibet has the least financial employees, with only 9,244 people, accounting for $2.01 \%$ of the ethnic regions, accounting for the country's total. $0.24 \%$. The number of employees in Inner Mongolia is 11.01 times that of Tibet, which is a huge gap. The number of employees per 10,000 people in the four provinces of Guangxi, Guizhou, Yunnan, and Xinjiang is lower than the national average. Among them, the three provinces of Guangxi, Guizhou, and Yunnan are still lower than the average of ethnic regions. However, the number of employees per 10,000 people in Inner Mongolia and Ningxia provinces is much higher than the national level. This shows that there is an imbalance in the geographical distribution of employees in financial institutions in ethnic areas, and there are large differences between regions.

\subsection{Deposits and loans of financial institutions in ethnic areas}

From the 2016 GDP statistics of all provinces and cities in the country released by the National Bureau of Statistics, as of the end of 2016, the balance of deposits and loans in ethnic areas accounted for $8.46 \%$ and $11.14 \%$ of the country's total. The GDP of ethnic regions accounted for $10.77 \%$ of the country's total, which can indicate that the total deposits in ethnic regions are relatively low and have not kept pace with GDP development. Among ethnic regions, Yunnan has the highest deposit balance, reaching 2.79 trillion yuan, accounting for $21.20 \%$ of ethnic regions and $1.79 \%$ of the country. Tibet has the smallest deposit balance, only 0.44 trillion yuan. It accounts for $3.34 \%$ of the minority areas, accounting for $0.28 \%$ of the country's total. The balance of deposits in Yunnan is 6.34 times that of Tibet, with a large gap. Yunnan still has the highest loan balance, reaching 2.35 trillion yuan, and the least is Tibet, only 0.30 trillion yuan, which is 7.83 times the difference, a huge gap. This shows that the development of deposits and loans in ethnic areas is extremely uneven, and the gap is obvious.

\section{Construction and measurement of financial exclusion index \\ 3.1 Construction of financial indexes}

Gao Peixing et al. (2011) condensed the six dimensions into four main dimensions, including geographic exclusion, marketing exclusion, evaluation exclusion, conditional exclusion, and price exclusion, using inter-provincial data to analyze the regional differences in rural financial exclusion. Tao Lei (2013) improved on this basis and studied the problem of financial exclusion in ethnic minority areas. This article combines the two research theories and the availability of data to construct a measurement index for the financial exclusion index.

Table 1. Agency indicators of various dimensions of financial support

\begin{tabular}{l|l|l}
\hline Dimension & Index & Calculation method \\
\hline $\begin{array}{l}\text { Geographical support (breadth of } \\
\text { financial services) }\end{array}$ & $\begin{array}{l}\text { Geographical Distribution Density of } \\
\text { Financial Employees }\end{array}$ & $\begin{array}{l}\text { Number of employees/land area (per square } \\
\text { kilometer) }\end{array}$ \\
\hline $\begin{array}{l}\text { Marketing support (depth of } \\
\text { financial services) }\end{array}$ & $\begin{array}{l}\text { Distribution density of financial } \\
\text { practitioners }\end{array}$ & $\begin{array}{l}\text { Number of financial employees/population (per } \\
10,000 \text { people) }\end{array}$ \\
\hline $\begin{array}{l}\text { Conditional support, price } \\
\text { support }\end{array}$ & $\begin{array}{l}\text { Per capita deposit level } \\
\text { Per capita loan level } \\
\text { Loan-to-deposit ratio in ethnic areas }\end{array}$ & $\begin{array}{l}\text { Various deposit balances/population (per person) } \\
\text { Various loan balances/population (per person) } \\
\text { Balance of various deposits/balance of various } \\
\text { loans }\end{array}$ \\
\hline $\begin{array}{l}\text { Evaluation support (Utilization } \\
\text { of financial services) }\end{array}$ & $\begin{array}{l}\text { Proportion of deposits in GDP } \\
\text { Proportion of loans to GDP }\end{array}$ & $\begin{array}{l}\text { Various deposit balances/GDP (\%) } \\
\text { Balance of various loans/GDP (\%) }\end{array}$ \\
\hline
\end{tabular}

Note: The bank credit expansion indicator is based on the percentage of the annual loan balance of the ethnic regions over the region's income in the previous year.

\subsection{Measurement of Financial Exclusion Index}

First, standardize each indicator. If the units and the degree of variation of different variables are different, this makes it difficult to interpret the coefficients in practice. The purpose of standardization is to unify the value range of each index into the interval of $[0,1]$, 
avoid unit inconsistency, so as not to be affected by dimension and order of magnitude. Here we mainly use the dispersion standardization method, also called 0-1 standardization, which is a linear transformation of the original data so that the result falls into the $[0,1]$ interval. The specific method is to subtract the observed value in a variable (the minimum value) of the variable is then divided by the range of the variable. The calculation formula is as follows:

$$
X_{i}=\frac{x_{i j}-m_{j}}{M_{j}-m_{j}}
$$

Among them of $M_{j}$ : the maximum value of the evaluation index; $m_{j}^{j}$ : the minimum value of the evaluation index; $x_{i j}$ : the actual value of the evaluation index. It is a variety of proxy indicators after standardization, and the subscript is to distinguish different proxy indicators.

Second, the weight calculation. For each evaluation index, the weighted average method is used to comprehensively measure the financial exclusion index, and the weight calculation method is carried out in the following steps:

(1)Calculate the coefficient of variation: $C V_{j}=\frac{S_{j}}{\bar{x}_{j}}$;

(2)Calculate the weight value: $\omega_{j}=\frac{C V_{j}}{\sum_{j=1}^{n} C V_{j}}$

Among them of $C V_{j}$ : the coefficient of variation of the $\mathrm{j}$-th evaluation index; $S_{j}$ : the standard deviation of the $\mathrm{j}$-th evaluation index; $\bar{x}_{j}^{j}$ : the average value of the $\mathrm{j}$-th evaluation index; $\omega_{j}$ : the weight corresponding to the $\mathrm{j}$-th evaluation index, and $0 \leq \omega_{j} \leq 1$.

Finally, calculate the financial exclusion index. Based on the above analysis and results, the financial exclusion index measurement formula can be derived:

$$
I F E_{i}=1-\sum_{j=1}^{7} \omega_{j} X_{i j}
$$

$I F E_{i}$, it is an index used to measure the degree of comprehensive financial exclusion in different ethnic regions. The subscripts $(i)$ represent different regions. The index reflects information of various dimensions.

\section{Empirical analysis \\ 4.1 Data source}

The selected sample includes data of ethnic autonomous areas in more than 20 provinces, autonomous regions, and municipalities directly under the Central Government. These data are distinguished by provincial units, not only including data from Inner Mongolia, Guangxi, Tibet, Ningxia, and Xinjiang Autonomous Regions and other ethnic regions and provinces, but also including aggregate data of ethnic minority autonomous prefectures and autonomous counties from provinces such as Liaoning, Jilin, Heilongjiang, Gansu, Qinghai, Hebei, Zhejiang, Hubei, Hunan, Chongqing, Sichuan, Guangdong, Hainan, Guizhou, and Yunnan. These data are compiled according to "China County Statistical Yearbook 2014", mainly for research and analysis of 2013 data. After removing samples with missing or incomplete data, a total of 485 valid samples were selected. The collected data is mainly through the compilation of the "2013 China Regional Financial Operation Report" published on the website of the China Banking Regulatory Commission and the 2014 "China County Economic Accounting Yearbook".

Using the formula $\mathrm{Y}_{j}=\ln \left(\frac{I F E_{j}}{1-I F E_{j}}\right)$ to perform Logit transformation on the original financial exclusion index, IFE becomes a monotonically increasing function after the transformation, and the transformation is the same as the original order, and the value range is $(-\infty,+\infty)$.

\subsection{Assumptions and description of related variables} 4.2.1 Research hypothesis

In order to carry out theoretical analysis better, we have made a series of research hypotheses, the validity of which remains to be tested. The details are as follows: (1) H1: Assuming that under the same other conditions, raising the level of regional economic development, increasing residents' economic income, and improving financial infrastructure can reduce the degree of local financial exclusion.

(2) H2: It is assumed that under the same other conditions, increasing the education level of residents and raising the cultural level of residents can reduce the degree of local financial exclusion.

(3) H3: Assuming that under the same other conditions, the government can reduce the degree of local financial exclusion by improving work efficiency, increasing support and exerting government functions.

4.2.2 Related variable description

Table 1 shows the description of the relevant variables in this study. 
Table 1 Description of related variables

\begin{tabular}{|c|c|c|c|}
\hline Variable type & Variable name & abbreviations & Variable's description \\
\hline Explained variable & $\begin{array}{l}\text { Financial } \\
\text { Exclusion Index }\end{array}$ & Ife & $\begin{array}{l}\text { GDP growth rate per capita calculated at constant prices in } \\
1994\end{array}$ \\
\hline \multirow{5}{*}{$\begin{array}{l}\text { Explanatory } \\
\text { variables }\end{array}$} & GDP per capita & $\mathrm{G}$ & GDP/person \\
\hline & $\begin{array}{l}\text { Financial } \\
\text { infrastructure }\end{array}$ & Infrastructure & $\begin{array}{l}\text { This variable is approximated by the telephone penetration } \\
\text { rate of each region. The calculation formula is telephone } \\
\text { penetration rate = number of local phone users/total } \\
\text { population. The higher the penetration rate, the better the } \\
\text { infrastructure. }\end{array}$ \\
\hline & $\begin{array}{l}\text { Education levelof } \\
\text { residents }\end{array}$ & Edu & $\begin{array}{l}\text { This variable uses the ratio of the number of students in } \\
\text { ordinary middle schools in each county to the total } \\
\text { population as a proxy indicator. The larger the ratio, the } \\
\text { higher the education level of residents. }\end{array}$ \\
\hline & $\begin{array}{l}\text { Government } \\
\text { support }\end{array}$ & Gs & $\begin{array}{l}\text { This variable uses local per capita fiscal expenditure } \\
\text { (logarithm) as a proxy indicator. The more fiscal expenditure, } \\
\text { the greater the local government support. }\end{array}$ \\
\hline & $\begin{array}{l}\text { Urban-rural } \\
\text { differences }\end{array}$ & Urban & $\begin{array}{l}\text { This variable is a dummy variable. The degree of } \\
\text { urbanization in municipal districts and county-level cities is } \\
\text { relatively high, with a value of } 1 \text { representing cities; the } \\
\text { degree of urbanization in counties and banners is low, with a } \\
\text { value of } 0 \text { representing rural areas. }\end{array}$ \\
\hline
\end{tabular}

Note: The data of the proportional nature calculated in the above table are in percentage form.

\subsection{Modeling}

After explaining the definitions of the relevant variables, we established a multiple regression model in order to test the three research hypotheses proposed earlier. The specific form of the model is as follows:

$Y_{i}=\beta_{0}+\beta_{1} X_{i 1}+\beta_{2} X_{i 2}+\beta_{3} X_{i 3}+\beta_{4} X_{i 4}+\beta_{5} X_{i 5}+\beta_{6} X_{i 6}+\beta_{7} X_{i 7}+\varepsilon$

Among them of $Y_{i}$, it represents the degree of financial

exclusion in each region, which $\beta_{0}$ is the intercept term, $\beta_{\mathrm{j}}(\mathrm{j}=1,2, \ldots, 7)$ is the coefficient corresponding to each independent variable, and the specific value is obtained through estimation, which $\mathcal{E}$ is a random error term.

\subsection{Descriptive statistical analysis}

Perform statistical analysis on the corresponding measurement indicators of the financial exclusion index. The calculation results of each step are shown in the following table:

Table 2.Descriptive Statistics

\begin{tabular}{|l|r|r|r|r|r|}
\hline & $\mathrm{N}$ & \multicolumn{1}{|c|}{ Minimum } & \multicolumn{1}{c|}{ Maximum } & \multicolumn{1}{c|}{ Mean } & \multicolumn{1}{c|}{ Std. Deviation } \\
\hline LDR & 485 & .0397583 & $6.3985185 \mathrm{E} 2$ & $2.889102131 \mathrm{E} 0$ & $2.9278977392 \mathrm{E} 1$ \\
\hline $\mathrm{DR}$ & 485 & .012831 & 2.652519 & .60504196 & .308038299 \\
\hline PR & 485 & .001275 & .957367 & .12090629 & .093454814 \\
\hline Narea & 485 & .02497 & $2.89888 \mathrm{E} 2$ & $1.4681774 \mathrm{E} 1$ & 25.58061118 \\
\hline LR & 485 & .000276 & 2.240475 & .56679479 & .333268230 \\
\hline $\mathrm{AL}$ & 485 & .00045 & 54.37148 & $1.8004458 \mathrm{E} 0$ & 3.27985689 \\
\hline AD & 485 & .0250 & 20.5719 & $1.577245 \mathrm{E} 0$ & 1.5841599 \\
\hline Valid N (listwise) & 485 & & & & \\
\hline
\end{tabular}

Table 3. Calculation results and analysis of IFE indicators

\begin{tabular}{|c|c|c|c|c|c|c|c|c|}
\hline Index & $\begin{array}{c}\text { Number of } \\
\text { samples }\end{array}$ & Mean & Max & Min & Max-Min & $\begin{array}{l}\text { Standard } \\
\text { deviation }\end{array}$ & $\begin{array}{c}\text { Coefficient of } \\
\text { variation }\end{array}$ & Weight \\
\hline LDR & 485 & 2.889102 & 639.8519 & 0.039758 & 639.8121 & 29.27898 & 10.13428 & 0.611503 \\
\hline DR & 485 & 0.605042 & 2.652519 & 0.012831 & 2.639689 & 0.308038 & 0.509119 & 0.03072 \\
\hline PR & 485 & 0.120906 & 0.957367 & 0.001275 & 0.956091 & 0.093455 & 0.772952 & 0.04664 \\
\hline Narea & 485 & 14.68177 & 289.8876 & 0.024969 & 289.8627 & 25.58061 & 1.742338 & 0.105133 \\
\hline LR & 485 & 0.566795 & 2.240475 & 0.000276 & 2.2402 & 0.333268 & 0.587987 & 0.035479 \\
\hline $\mathrm{AL}$ & 485 & 1.800446 & 54.37148 & 0.00045 & 54.37103 & 3.279857 & 1.821692 & 0.109921 \\
\hline \multirow[t]{2}{*}{$\mathrm{AD}$} & 485 & 1.577245 & 20.57185 & 0.02503 & 20.54682 & 1.58416 & 1.004384 & 0.060605 \\
\hline & & & & & & & 16.57276 & \\
\hline
\end{tabular}


Table 4. Pearson correlation analysis

\begin{tabular}{|c|c|c|c|c|c|c|c|c|c|}
\hline & Y & UC & Inf & G & GR & Income & Eff & Gs & Edu \\
\hline Y & 1.000 & & & & & & & & \\
\hline UC & -0.448 & 1.000 & & & & & & & \\
\hline Inf & -0.415 & 0.460 & 1.000 & & & & & & \\
\hline G & -0.227 & 0.166 & 0.354 & 1.000 & & & & & \\
\hline GR & -0.227 & 0.166 & 0.354 & 1.000 & 1.000 & & & & \\
\hline Income & -0.275 & 0.169 & 0.368 & 0.897 & 0.897 & 1.000 & & & \\
\hline Eff & -0.203 & 0.327 & 0.335 & 0.499 & 0.499 & 0.348 & 1.000 & & \\
\hline Gs & -0.074 & 0.018 & 0.311 & 0.719 & 0.719 & 0.739 & -0.022 & 1.000 & \\
\hline Edu & -0.426 & 0.320 & 0.261 & 0.116 & 0.116 & 0.168 & 0.027 & 0.047 & 1.000 \\
\hline
\end{tabular}

Table 4 shows the Pearson correlation coefficient between each variable. From the data in the above table, it can be seen that Y (Financial Exclusion Index) has a negative correlation with all variables. At the same time, the correlation coefficients of most explanatory variables have not reached 0.5 , and the correlation between the variables is not strong, indicating that the established model does not have serious multicollinearity.

Table 5 Statistical description of related variables

\begin{tabular}{|c|c|c|c|c|c|c|}
\hline Variable & $\begin{array}{c}\text { Observed } \\
\text { value }\end{array}$ & Min & Max & Mean & Median & $\begin{array}{c}\text { Standard } \\
\text { deviation }\end{array}$ \\
\hline UC & 485 & 0 & 1 & 0.14 & 0 & 0.348 \\
\hline Infrastructure & 485 & 0.000000 & .576054 & 0.10466096 & 0.07187273 & 0.093036115 \\
\hline G & 485 & 0.385445 & 43.53780 & 3.57129426 & 1.99726538 & 5.313343283 \\
\hline GR & 485 & 0.091974 & 10.38890 & 0.85217483 & 0.47658332 & 1.267858949 \\
\hline Income & 485 & 0.014988 & 4.418118 & 0.26879920 & 0.13086136 & 0.455434832 \\
\hline Eff & 485 & 0.363827 & 25.55814 & 3.78719024 & 2.91709180 & 2.792802506 \\
\hline Gs & 485 & 0.076421 & 7.087200 & 0.95604913 & 0.0455050 & 0.824071501 \\
\hline Edu & 485 & 0.012883 & 0.121506 & 0.04721173 & 0.6794697 & 0.016448088 \\
\hline Y & 485 & 1.267756 & 5.542935 & 3.38854579 & 3.4162397 & 0.502458561 \\
\hline
\end{tabular}

Table 5 is the result of descriptive statistics on each variable. It can be seen from the table: First, the difference between the average value and the median of each variable is not large, indicating that the variables are generally symmetrically distributed, which will help improve the reliability of quantitative analysis. Second, in the sample, the Ordos Dongsheng District in Inner Mongolia has the lowest financial exclusion index, with an exclusion index of 1.267756, and the Shule County in Kashgar, Xinjiang has the highest degree of financial exclusion, with 5.54293. There is a large gap between the two, which indicates that the financial exclusion of counties (cities) in the ethnic regions has greater regional differences. Third, in terms of the average GDP of ethnic regions, the Subei Mongolian Autonomous County in Jiuquan City, Gansu
Province has the highest level, indicating that the strategy of developing the western region has played a significant role. Fourth, the average value of the data on the level of urban-rural difference is 0.14 , indicating that there is a certain gap between urban and rural areas. Fifth, there is a relatively large standard deviation of GDP in the ethnic regions, which shows that the counties (cities) in the ethnic regions have large differences due to the large differences in the economic environment they face. Sixth, in terms of government financial support, Subei Mongol Autonomous County in Jiuquan City, Gansu Province, in ethnic regions, gave the most support, while Zhenfeng County, Qianxinan Buyi and Miao Autonomous Prefecture in Guizhou Province, provided very low financial expenditure per unit. The support is minimal.

\subsection{Regression analysis of factors affecting financial exclusion in China's ethnic regions}

Table 6.Model Summary

\begin{tabular}{|c|c|c|c|c|c|c|c|c|c|}
\hline \multirow[b]{2}{*}{ Model } & \multirow[b]{2}{*}{$\mathrm{R}$} & \multirow[b]{2}{*}{ R Square } & \multirow[b]{2}{*}{$\begin{array}{l}\text { Adjusted R } \\
\text { Square }\end{array}$} & \multirow[b]{2}{*}{$\begin{array}{l}\text { Std. Error of } \\
\text { the Estimate }\end{array}$} & \multicolumn{5}{|c|}{ Change Statistics } \\
\hline & & & & & $\begin{array}{l}\text { R Square } \\
\text { Change }\end{array}$ & F Change & df1 & df2 & Sig. F Change \\
\hline 1 & $.547^{\mathrm{a}}$ & .300 & .289 & .441981720 & .300 & 29.165 & 7 & 477 & .000 \\
\hline
\end{tabular}

a. Predictors: (Constant), Edu, Eff, Gs, UC, Infrastructure, Income, GR 
Table 7.Regression analysis and model parameter estimation

\begin{tabular}{|c|c|c|c|c|c|c|}
\hline \multirow[b]{2}{*}{ Model } & \multicolumn{2}{|c|}{ coefficient } & \multirow[b]{2}{*}{$\mathrm{t}$ value } & \multirow[b]{2}{*}{ Sig. } & \multicolumn{2}{|c|}{ Collinearity Statistics } \\
\hline & $\begin{array}{c}\text { B } \\
\text { Confidence interval }\end{array}$ & Std. Error & & & Tolerance & VIF \\
\hline $\begin{array}{c}\text { (Constant) } \\
\text { Confidence } \\
\text { interval }\end{array}$ & $\begin{array}{c}3.757 \\
(3.585, \quad 3.930)\end{array}$ & .088 & 42.770 & .000 & & \\
\hline UC & $\begin{array}{c}-0.369 \\
(-0.506, \quad-0.233)\end{array}$ & .069 & -5.327 & .000 & 0.695 & 1.438 \\
\hline Infrastructure & $\begin{array}{c}-1.134 \\
(-1.671,-0.597)\end{array}$ & .273 & -4.150 & .000 & .624 & 1.602 \\
\hline GR & $\begin{array}{c}-0.034 \\
(-0.126,0.058)\end{array}$ & .047 & -0.719 & .473 & .115 & 8.723 \\
\hline Income & $\begin{array}{c}-0.265 \\
(-0.476, \quad-0.054)\end{array}$ & .107 & -2.466 & 0.014 & .168 & 5.936 \\
\hline Eff & $\begin{array}{c}0.020 \\
(-0.003, \quad 0.043)\end{array}$ & .012 & 1.686 & .093 & .374 & 2.674 \\
\hline Gs & $\begin{array}{c}0.144 \\
(0.048, \quad 0.239)\end{array}$ & .049 & 2.958 & .003 & .251 & 3.978 \\
\hline Edu & $\begin{array}{c}-6.850 \\
(-9.472,-4.228)\end{array}$ & 1.335 & -5.133 & .000 & .826 & 1.210 \\
\hline
\end{tabular}

Table 6 and Table 7 are the results of the empirical analysis of the factors affecting financial exclusion in ethnic regions. The OLS basic regression is used to perform cross-sectional regression of the model. The adjusted coefficient of determination (Adjusted R Square) after regression is 0.289 , and $\mathrm{F}$ The statistical value is significant at the $5 \%$ level, which indicates that the overall fitting effect is ideal.

\section{Research conclusion}

Based on the above analysis, the main conclusions of this paper are as follows:

Looking at the overall situation, the current situation of financial exclusion in my country's ethnic minority areas has both good and worrying aspects, but relatively speaking, financial exclusion in ethnic areas is relatively serious and urgently needs to be addressed. By analyzing the distribution of financial outlets in ethnic areas, the geographical distribution of financial outlets in ethnic areas is very sparse, but in terms of population distribution density, they are relatively optimistic, basically reaching the national average level; the development of financial business in ethnic areas is almost entirely state-owned Commercial banks, rural credit cooperatives and postal savings institutions have monopolized the three traditional financial entities; due to the role of market mechanisms, it is difficult for ethnic regions to attract joint-stock commercial banks to settle in; urban credit cooperatives and rural credit cooperatives have not kept up with the joint-stock reforms The progress of the times is relatively backward; there is a policy preference for financial development in ethnic areas; cooperative finance and new rural institutions have achieved rapid development in ethnic areas, especially village banks and rural mutual aid cooperatives. The number of institutions has grown by leaps and bounds.

The problem of financial exclusion has systemic characteristics, and various aspects such as politics, society, economy, and culture will have different degrees of influence on it. Therefore, ethnic regions cannot blindly imitate the experience of developed countries or regions to control financial exclusion. It is necessary to closely integrate the actual conditions in ethnic areas, formulate reasonable guidelines and policies, and take the path of governance with local characteristics. In terms of economic and financial impacts, taking measures to speed up the process of urbanization, enhance competition in the financial industry, increase residents' income levels, promote residents' employment, and improve the construction of financial infrastructure can effectively reduce local financial exclusion. degree.

There are many reasons for financial exclusion. Therefore, the governance of financial exclusion in China's ethnic minority areas is also a systematically complex project that requires the cooperation and joint efforts of financial institutions, demand subjects, and governments and other relevant stakeholders. Among them, the government should play a leading role, guide the direction of financial exclusion governance, and create an environment of reasonable competition in the financial market in ethnic areas, which will help improve the level of operation and management and further expand the scope of financial services.

\section{Countermeasures for financial exclusion in China's ethnic minority areas}

Based on the previous analysis and research on the current situation of financial exclusion in my country's ethnic minority areas and the measurement of financial exclusion index, this article puts forward countermeasures and suggestions for managing financial exclusion in ethnic areas based on the above analysis results, mainly considering the following aspects.

\subsection{Reasonably increase financial outlets and improve financial organization.}

Financial exclusion in ethnic regions is largely due to the structure of financial outlets that emphasizes urban 
and rural areas. Therefore, in order to enable all social groups to have access to basic financial services, especially the poor groups suffering from severe financial exclusion, financial outlets should be reasonably set up in ethnic areas. However, the target for the establishment of new outlets should be remote and rural areas, and strive to establish fixed business outlets in all towns and towns where the financial services are blank. In order to control financial exclusion in ethnic areas, a complete financial organization system is needed, so that the organizational form of financial institutions can better adapt to the characteristics of financial exclusion groups, so as to better meet the financial needs of financial exclusion groups.

6.2 Appropriately increase financial supply and curb the outflow of financial resources.

First of all, we must pay attention to the training of financial talents, take appropriate measures to provide more preferential policies to attract high-quality financial talents who work in ethnic areas for support and long-term work, and increase exchanges and cooperation with financial talents in other regions. Improve the overall quality of the financial industry team in ethnic regions, and lay a human resource foundation for ethnic regions to expand the scope of financial services and improve financial innovation capabilities.

Secondly, the minority areas should increase the supply of credit funds appropriately. When financial institutions have insufficient fund positions to support the development and construction, reform and development, poverty alleviation and income generation of the minority areas, they should increase the scale of re-loans and rediscount indicators accordingly, and grant financial institutions re-lending and Rediscount support.

In addition, ethnic regions can establish a docking mechanism between large-scale institutions and smalland medium-sized institutions. Large-scale institutions provide wholesale loans to small and medium-sized institutions, and small and medium-sized institutions can provide retail credit services to low-income groups. Under this mechanism, large financial institutions no longer mainly provide microfinance services to a large number of dispersed low-income groups, but provide large-scale loans to small and medium-sized institutions to give play to their comparative advantages; while small and medium-sized institutions obtain wholesale loans from large institutions, It focuses on providing microfinance services, and the funds obtained from large institutions are distributed to the majority of low-income people.

6.3 Innovate economic development ideas and increase residents' income.

The economic development of ethnic regions should be based on local realities, innovate industrial development ideas, give full play to their comparative advantages in resource endowments and late-comer advantages in high-tech, and take advantage of high-quality and efficient agriculture, tourism, characteristic cultural industries, and high-tech industries. Development is the focus (Ren Zhijun, 2007). It can be seen from the empirical analysis results of this article that financial exclusion is affected by the income level and employment status of residents, and the degree of local financial exclusion will decrease significantly with the increase in income level and the improvement of employment status. With the increase in income levels, financial exclusion in ethnic areas will certainly be alleviated, and the alleviation of financial exclusion will create conditions for further increases in income levels. The increase in income levels will eventually form a positive interaction with the governance of financial exclusion.

In ethnic areas with complex social environments, the governance of financial exclusion requires not only to increase the income level of residents, but also to properly adjust the income distribution gap, because excessive income gaps will cause other problems in the process of financial development. The specific measures are: First, actively promote the development of new urbanization, strive to achieve equalization of basic public services in urban and rural areas, promote the further increase of the proportion of secondary and tertiary industries in rural areas, establish a relatively complete urban and rural employment service system, and attract rural surplus labor to turn to cities. .

\subsection{Strengthen infrastructure construction,} introduce competition and encourage innovation.

In terms of geographical distribution, ethnic regions in China are mainly distributed in border provinces or remote areas. Due to the constraints of geographical environment and historical factors, the infrastructure of transportation and communication is not perfect, which makes the exogenous financial transaction cost more expensive. . From the above empirical analysis, we can see that there is a significant negative correlation between the state of financial infrastructure and the degree of local financial exclusion, which also reflects that infrastructure construction plays a very important role in the governance of financial exclusion. A sound financial infrastructure can not only promote the increase in the diversity of modern financial services, but also solve the problem of information asymmetry, thereby reducing the cost of financial institutions to provide services and reducing financial exclusion. Therefore, ethnic regions should increase investment in infrastructure construction, promote the wide application of information technology in the financial industry, expand and broaden the field of payment and settlement, realize the effective extension of the financial technology network in ethnic regions, and enable financial services to cover people in need . Infrastructure construction can improve the operating environment of the financial system in ethnic regions. However, to completely cure the persistent disease of financial exclusion, the correct idea should be to 
introduce reasonable competition from financial institutions in ethnic regions. Only under the incentive of market competition can financial institutions truly have the motivation to design products that meet the characteristics of different groups of people, and ultimately achieve full coverage of financial services in ethnic areas.

\subsection{Improve the level of financial education and reduce other social exclusion}

The level of education will affect the ideology and financial habits of a region. The empirical results of this paper show that one of the important reasons for financial exclusion is the education level of a region, and low education level often leads to a higher degree of financial exclusion. Residents in ethnic areas lack financial knowledge, which prevents them from understanding and accepting financial products, and they are prone to self-exclusion. Therefore, only by actively promoting the innovation and development of financial education, raising the level of financial education, and eliminating differences in financial knowledge, can we gradually realize financial inclusion in ethnic regions. However, this is obviously a long-term process and cannot be accomplished overnight. It requires long-term vision from policy makers and financial participants.

\section{References:}

1. Tao Lei. Research on Financial Exclusion in China's Ethnic Minority Areas[D]. Southwestern University of Finance and Economics, 2013.

2. Yang Hong, Zhang Ke. Research on the Spatial Effects and Influencing Factors of Financial Exclusion_-Based on the Empirical Analysis of Yunnan Province[J].Financial Theory and Practice,2020(06):47-56.

3. Yin Zhichao, Geng Ziyu, Pan Beixiao. Financial exclusion and household poverty in China: an empirical study based on CHFS data[J].Research on Financial Issues,2019(10):60-68

4. Yu Wenmei, Cao Qiang. Game analysis of financial poverty alleviation from the perspective of financial exclusion $[\mathrm{J}]$. Statistics and Decision, 2018,34(10):42-46.

5. Xu Jingping, Zhang Ronggang, Zhang Qin. Rural financial exclusion, financial poverty alleviation and government supervision efficiency[J]. Research on Financial Issues, 2018(02):102-107.

6. Liu Yuhong. Correlation analysis of the differences in regional rural financial exclusion in my country[J]. Economic Research Guide, 2020(08): 124-125+132.

7. Wang Jiao, Yao Shuang, Wang Wenrong. Research on the Defects of Digital Financial Inclusion and the Generation of New Financial Exclusion__ Based on the Rural Perspective[J]. Agricultural Economics,2020(02):94-97. 